|| ISSN(online): 2589-8698 || ISSN(print): 2589-868X || International Journal of Medical and Biomedical Studies

Available Online at www.ijmbs.info

Volume 3, Issue 2; February: 2019; Page No. 138-142

PubMed (National Library of Medicine ID: 101738825)

Index Copernicus Value 2017: 40.03

\title{
STUDY OF LIFE STYLE, DIETARY PATTERN AND BMI OF YOUNG WOMEN AGED BETWEEN 20-40 YEARS
}

${ }^{1}$ Priyam Sharma, ${ }^{2 *}$ Akshay Berad

${ }^{1}$ Clinical Dietitian, Diabetes Educator, Pilates Trainer level-4, Delhi, India.

${ }^{2 *}$ Associate Professor, Dept. of Physiology, RIMS, Adilabad, Telangana, India.

Article Info: Received 4 February 2019; Accepted 28 February. 2019

Cite this article as: Sharma, P., \& Berad, A. (2019). STUDY OF LIFE STYLE, DIETARY PATTERN AND BMI OF YOUNG WOMEN AGED BETWEEN 20-40 YEARS. International Journal of Medical and Biomedical Studies, 3(2).

DOI: https://doi.org/10.32553/ijmbs.v3i2.126

Address for Correspondence: Akshay Berad, Associate Professor, Dept. of Physiology, RIMS, Adilabad, Telangana, India.

Conflict of interest: No conflict of interest.

\section{Abstract}

Obesity is increasing at an alarming rate throughout the world and has become a global problem. The World Health Organisation (WHO) has declared overweight as one of the top 10 health risks in the world and one of the top five in developed nations (WHO, 2002) In many developing countries, with increasing urbanization, mechanization of jobs and transportation, availability of processed and fast foods, and dependence on television for leisure, people are fast adopting less physically active lifestyles and consuming more "energy-dense, nutrient-poor" diets. The objective of the study was to investigate the prevalence of overweight issues and obesity by recording the body mass index (BMI) and explore the dietary habits, physical activities (PAs), and lifestyles of females between 20-40 years of age. Questionnaire was used in this study for data collection about general information, body mass index, dietary habits and Lifestyle of 20 female subjects. It was observed that 3 females were underweight, 9 were normal weight and 8 were overweight and obese. From the results of the study, we can conclude that the incidence of being overweight and obese is increasing . The awareness about Physical activities healthy diet/lifestyle, and consequences of overweight and obesity on their health and profession must be increased among the young females to avoid future complications.

Key words: Body Mass index, lifestyle, dietary habits, Physical activity

\section{Introduction:}

Obesity is the leading non-communicable disease pandemic of the post-industrialization and ongoing digital revolution period. Recent trend analysis (1975-2016) showed an increasing trend in

the prevalence of overweight and obesity among adults, adolescents and children across the world [1] with an estimated obesity cases of 670 million adults and 124 million young people aged 5-19 years in 2016 [1]. Despite of these high estimates, critiques still argued that the figures might have been much higher if different diagnostic criteria for overweight and obesity other than body mass index (BMI) were used $[2,3]$. With rapidly mushrooming and poorly planned urban centers, improving economic prospects and ongoing nutrition transition, Indians are experiencing an upsurge in the prevalence of overweight and obesity, especially among women of reproductive age [4, 5] Being 
overweight and obesity are defined as abnormal or excessive fat accumulation that may impair health. It is the most common nutritional disorder in developed countries and its percentage is increasing in the developing countries also.[6,7] Being overweight and obese can lead to adverse metabolic changes, including increases in blood pressure, unfavorable cholesterol levels, and increased insulin resistance. They raise the risk of coronary heart diseases, stroke, type II diabetes, atherosclerosis, gallbladder disease, hypertension, kidney failure, and many forms of cancers, particularly breast cancer. It has become one of the most serious public health challenges of the 21st century. $[8,9]$ An unhealthy diet is a major modifiable behavioural risk factor in the development of obesity. Although a variety of dietary recommendations for the management and prevention of obesity have been proposed, evidence is inconsistent and varies between measures of dietary intake used. Furthermore, the role of diet in obesity associated health disorders is an important consideration for the development of dietary guidelines. Physical inactivity ultimately leading to overweight condition and obesity is also a leading risk factor for the global deaths. The benefits of regular physical PA have been clearly set out across the lifespan. A strong body of evidence, comprising both observational and experimental research, indicates that regular participation in PA among young people provides immediate and long-term benefits for physical and psychological well-being.[10,11,12]. The objective of the study was to investigate the prevalence of overweight issues and obesity by recording the body mass index (BMI) and explore the dietary habits, physical activities (PAs), and lifestyles of females between 20-40 years of age.

\section{Material and methods:}

The study was conducted by nutritionist Priyam Sharma in Delhi .Questionarre was prepared which included question about general information of subjects, lifestyle, dietary habits, physical activities, and about sleep. 20 female subjects were included in study. They were between age 20-40 years. Age, height, weight, and Body mass Index was recorded from subjects. Mean and standard deviation values were calculated. The data obtained from questionarre was segregated and studied. Data was divided into general information about subjects, lifestyle of subjects, and dietary pattern of subjects. BMI was calculated and divided into underweight, normal weight and overweight.

\section{Results:}

Table 1 shows data about general information of subjects .10 subjects were married and 10 were single. 4 subjects were educated upto graduation, 8 were post graduate and 8 had studied up to high school. 14 subjects were from urban area, 4 from rural and 2 were NRI. It also shows monthly income of subjects

Table 1: General information of subjects

\begin{tabular}{|l|l|l|l|}
\hline Marital status & Married & Single & \\
\hline Number of subjects & $\mathbf{1 0}$ & $\mathbf{1 0}$ & \\
\hline Level of education & Graduate & Post Graduate & Upto high school \\
\hline & $\mathbf{4}$ & $\mathbf{8}$ & $\mathbf{8}$ \\
\hline Origin & Rural & Urban & NRI \\
\hline & $\mathbf{4}$ & $\mathbf{1 4}$ & $\mathbf{2}$ \\
\hline Monthly income & Less than 10000 Rs & $\mathbf{1 0 0 0 0 - 2 0 0 0 0 ~ R s ~}$ & $\mathbf{2 0 0 0 0 - 8 0 0 0 0 ~ R s ~}$ \\
\hline & $\mathbf{2}$ & $\mathbf{6}$ & $\mathbf{1 2}$ \\
\hline
\end{tabular}

Table 2 shows Mean and SD values of age, height, weight amd BMI. BMI shows that mean BMI was on borderline of overweight of subjects. 
Table 2: Mean values of age, weight, height, and BMI

\begin{tabular}{|l|l|}
\hline Variables & Mean $\pm S D(n=20)$ \\
\hline Age (years) & $33.26 \pm 6.2$ \\
\hline Weight $(\mathrm{Kg})$ & $62 \pm 10.94$ \\
\hline Height $(\mathrm{cm})$ & $159 \pm 5.98$ \\
\hline Body mass index & $25.08 \pm 4.42$ \\
\hline
\end{tabular}

Table 3 shows that half of subjects take alcohol either ocassionaly or regularly, 16 subjects were nonsmokers, half of subjects had sleep less than 6 hours. 12 subjects had physical activities less than 30 minutes in a day.

This shows most of subjects had unhealthy lifestyle.

Table 3: Response to questions on lifestyle

\begin{tabular}{|l|l|l|}
\hline Alcohol intake & Yes & No \\
\hline Number of subjects & 10 & 10 \\
\hline Smoking & Yes & No \\
\hline Number of subjects & $\mathbf{4}$ & $\mathbf{1 6}$ \\
\hline Sleep hours in night & Less than 6 hours & More than 6 hours \\
\hline Number of subjects & $\mathbf{1 0}$ & $\mathbf{1 0}$ \\
\hline Physical Exercise daily & Less than $\mathbf{3 0}$ minutes & $\mathbf{3 0 - 6 0}$ minutes \\
\hline Number of subjects & $\mathbf{1 2}$ & $\mathbf{8}$ \\
\hline
\end{tabular}

Table 4 shows that 3 subjects were underweight. 9 subjects were normal BMI. 8 subjects were overweight and obese which is due to lack of physical activity and unhealthy diet, alcohol consumption.

Table 4: Body mass Index (kg/metre $\left.{ }^{2}\right)$

\begin{tabular}{|l|l|l|}
\hline BMI -Less than 20 & BMI-20-25 & BMI- More than 25 \\
\hline Under weight & Normal weight & Overweight \& obese \\
\hline 3 subjects & 9 subjects & 8 subjects \\
\hline
\end{tabular}

Table 5 shows data about dietary habits of subjects, half of subjects were nonvegetarian.. Daily fat intake was more in 8 subjects. 12 subjects had regular habit of eating junk food outside weekly. This shows most of subjects had unhealthy dieatary habits.

Table 5: Response to questions related to dietary habits

\begin{tabular}{|l|l|l|l|}
\hline Type of Diet & Vegeterian & Nonvegetarian & \\
\hline Number of subjects & 10 & 10 & \\
\hline Number of meals in a day & $\mathbf{2}$ & $\mathbf{3 - 4}$ & $\mathbf{5 - 6}$ \\
\hline Number of subjects & $\mathbf{6}$ & 10 & $\mathbf{4}$ \\
\hline Fat intake in grams & Less than 10 grams & About 10 grams & More than 10 grams \\
\hline Number of subjects & $\mathbf{4}$ & $\mathbf{8}$ & $\mathbf{8}$ \\
\hline Junk Food / weekly & Once & $\mathbf{2 - 3}$ times & More than 3 times \\
\hline Number of subjects & $\mathbf{8}$ & $\mathbf{1 0}$ & $\mathbf{2}$ \\
\hline
\end{tabular}




\section{Discussion:}

This high prevalence of the overweight and obese among the female subjects reflects the profound changes in social and behavioral patterns in general community. This high prevalence may be related to their dietary habits, which are usually irregular timings of meals, improper quality of food, eating of too much junk food, and eating mostly outside their homes. Percentage of eating three meals or more is higher for the overweight and obese students. The percentage of eating outside, consumption of snacks, cold drinks, and sweets is also higher for the overweight and obese this needs to be taken into consideration whenever a dietary education program is established for these overweight and obese female subjects. The PA contributes up to $50 \%$ of total daily energy expenditure, and there is evidence that active individuals have a healthier body weight and composition than inactive individuals. Physical inactivity and unhealthy diets are considered among the leading causes of major noncommunicable diseases, including cardiovascular disease, type II diabetes, and certain types of cancer, thus contributing substantially to the global burden of disease, death, and disability. The high prevalence of physical inactivity among females is of concern. Thus it emerges from the study that we should not put the issue of obesity on the back burner. It was found that there is a significant increase in overweight and obesity among women in Delhi during last four years. So attention should be paid on overweight and obesity coexisting with under nutrition at the national level. Several general and reproductive health problems were found significantly higher among overweight and obese women compared to normal women, therefore obese women should be given special attention by health providers and policy makers. There is an urgent need to recognize the gravity of the problem of obesity and therefore incorporate it in the general health system. A healthy lifestyle should be promoted to tackle this emerging health threat.

\section{Conclusion:}

The findings of this study suggest social patterning in the risk of overweight and obesity among young women of reproductive age in India. It points to the importance of considering women of reproductive age above 30 years and women living in affluent families as potential target group for public health policy and interventions. Further investigations might be needed to examine possible effect modification of educational attainment on overweight and obesity by household socio-economic status and the country's level of economic development. The awareness about PA, healthy diet/lifestyle, and consequences of overweight and obesity on their health and profession must be increased among the young women to avoid future complications.

\section{References:}

1. Abarca-Gomez, L., et al., Worldwide trends in body-mass index, underweight, overweight, and obesity from 1975 to 2016: a pooled analysis of 2416 population-based measurement studies in $128 \cdot 9$ million children, adolescents, and adults. The Lancet, 2017. 390 (10113): p. 2627-2642.

2. Reilly, J. J., et al., Determining the worldwide prevalence of obesity. The Lancet, 2018. 391 (10132): p. 1773-1774.

3. Amugsi, D. A., et al., Prevalence and time trends in overweight and obesity among urban women: an analysis of demographic and health surveys data from 24 African countries, 1991-2014. BMJ open, 2017. 7 (10): p. e017344.

4. Neupane, S., K. Prakash, and D. T. Doku, Overweight and obesity among women: analysis of demographic and health survey data from 32 Sub-Saharan African Countries. BMC Public Health, 2015. 16 (1): p. 30.

5. Ogden $\mathrm{CL}$, Carroll MD, Curtin LR, McDowell MA, Tabak CJ, Flegal KM. Prevalence of overweight and obesity in the United States, 1999-2004. JAMA 2006 Apr;295(13):15491555. 
6. Al MA, Ismail MS, Ahmed SM, Alharbi MH. Progressive changes in overweight and obesity during the early years of schooling among children in a central region of Saudi Arabia. Food Public Health 2012;2(5):159167.

7. Ng $M$, Fleming $T$, Robinson $M$, Thomson $B$, Graetz N, Margono C, Mullany EC, Biryukov S, Abbafati C, Abera SF, et al. Global, regional, and national prevalence of overweight and obesity in children and adults during 1980-2013: a systematic analysis for the Global Burden of Disease Study 2013. Lancet 2014 Aug 30;384(9945):766-781.

8. Khatib O. Non communicable diseases: risk factors and regional strategies for prevention and care. East Mediterr J 2004 Nov;10(6):778-783.

9. Al Hazza HM, Musaiger AO. Physical patterns and eating habits of adolescents living in major Arab cities. The Arab Teens lifestyle study. Saudi Med J 2010 Feb;31(2):210-211.

10. Dumith SC, Gigante DP, Domingues MR, Kohl HW. Physical activity changes during adolescence: a systematic review and a pooled analysis. Int J Epidemiol 2011 Jun;40(3):685-698.

11. Al-Nozha MM, Al-Hazzaa HM, Arafah MR, AlKhadra A, Al-Mazrou YY, Al-Maatouq MA, Khan NB, Al-Marzouki K, Al-Harthi SS, Abdullah $M$, et al. Prevalence of physical activity and inactivity among Saudis aged 3070 years: a population-based cross-sectional study. Saudi Med J 2007 Apr;28(4):559-568. 